\title{
Mothers as active contributors to post-earthquake recovery in Christchurch
}

\author{
Angelina Jennings, Nicky Stanley-Clarke and Polly Yeung, Massey University, New Zealand
}

\begin{abstract}
INTRODUCTION: An understanding of mothers as a subset of women who are active contributors to a recovery effort is crucial to building disaster resilience. This study explored the post-disaster experiences of mothers from the two Christchurch earthquakes in 2010 and 2011 to consider factors which both helped and hindered their recovery.

METHOD: This research was a qualitative study involving semi-structured interviews with six married mothers who were present during the 2010 and 2011 Christchurch earthquakes. Interviews focused on understanding the personal, environmental and psychological impacts of the earthquakes. Data were analysed using thematic analysis.
\end{abstract}

FINDINGS: Three key findings were established, highlighting: 1) Elements of resilience are essential for recovery; 2) mothers playing a constructive and proactive role in their community post-disaster; and 3) the importance of a sense of belonging to enhance post-disaster recovery.

CONCLUSION: While participants were affected practically and psychologically by the earthquakes, core characteristics of resilience such as positivity, hope, flexibility and adaptability were portrayed in supporting their post-disaster recovery. These mothers played an active role in the recovery of their community and felt a clear sense of belonging which enhanced their recovery.

IMPLICATIONS: Based on the findings of this study, social work skills such as utilising an emancipatory or strengths-based approach to intervention alongside a sound understanding of community participation can harness strengths through a sense of belonging, purpose and opportunity for pro-activity in disaster recovery.

KEYWORDS: mothers; disaster recovery; Christchurch earthquakes; resilience

\section{Introduction}

This article details the findings from a study that explored the post-disaster experiences of mothers after the 2010 and 2011 Christchurch earthquakes. The study occurred across 2015 and 2016 and considered factors which helped and which hindered the mothers' recovery in the aftermath of the earthquakes.
The study was a supervised research project completed as part of a master's degree in social work. The research found mothers experienced and recovered from the earthquakes in different ways, embodying resilient characteristics including positivity, hope, flexibility and adaptability. They also identified that belonging and contributing to a community after a disaster were very
AOTEAROA

NEW ZEALAND SOCIAL WORK 30(3), 19-30.

CORRESPONDENCE TO: Angelina Jennings angelinajennings@hotmail. com 
important in rebuilding their wellbeing and ability to recover post-disaster. The findings of this study provide new knowledge about mothers' experiences and highlight opportunities for social workers to work alongside mothers in ways that further support and enhance their resilience and post-disaster recovery.

\section{Resilience and motherhood in relation to disaster recovery}

Resilience is regarded as a key basis for recovery after disasters. It can be an attribute of individuals, communities or collectives; embodied within a process or set of actions and interactions (Gordon, Sutherland, Du Plessis, \& Gibson, 2014). Resilient people assist the recovery effort by having the ability to face reality with determination and being able to reframe adversity to make meaning and move on successfully. Those individuals who have previously managed adversity successfully learn skills, solutions and routines that allow them to repeat these actions in the future (Satici, 2016). The characteristics of resilience are protective factors in the aftermath of disaster. These characteristics support capacity building of people, communities and societies to anticipate, cope and develop from hazardous consequences, rebuilding and reconstructing their environment and ultimately facilitating recovery (Paton \& Johnston, 2006).

With more disasters happening in Aotearoa New Zealand, such as the Christchurch earthquakes 2010 and 2011, the Kaikoura earthquake in November 2016, and the Port Hill Fires in 2017, it is important to explore the concept of resilience beyond recovery. Resilience incorporates opportunities to improve upon previous situations, circumstances and environments (Chandler, 2014; van Kessel, Gibbs, \& MacDougall, 2015). To thrive in the face of adversity, individuals must have good problem-solving skills, self-confidence and self-efficacy. Resilience can involve people progressing towards a situation that has psychosocially and physically changed, rather than returning to a previous state and in the process reframing the situation from a negative experience to a positive one (Chandler, 2014). Some individuals, when facing adversity, demonstrate a capacity for growth, thriving and building on their strengths and resources to achieve positive outcomes. These individuals see opportunities for financial, business or social improvement and work hard with the resources available to them to make this happen (Nicholls, 2012).

Research has foregrounded women as strong-minded leaders of post-disaster recovery (Ariyabandu, 2009). They often take on many roles beyond the home environment and may embody strength, flexibility and resilience (Ariyabandu, 2009; Islam, Ingham, Hick, \& Mancok et al., 2017; McManus, 2015). Women are often the primary caregivers, pre-and post-disaster and, as such, their mental and physical needs can get overlooked as the needs of their dependants take priority (Enarson, 2009; Norris \& Wind, 2009). Studies have shown increased expectations felt by mothers to manage themselves and the needs of their children can lead to additional pressure on their mental and physical health as well as difficulties in sustaining recovery long term (Neria, Galea, \& Norris, 2009; Norris \& Wind, 2009).

Unsurprisingly, challenges that are inherent in motherhood become intensified after a natural disaster, which creates additional pressures for women who have responsibility for looking after others' needs alongside their own (Ariyabandu, 2009; Juran \& Trivedi, 2015). Together, these studies argue that practical and environmental issues impact on a mother's ability to provide a stable, secure environment for her children and an inability to do so would affect her psychological wellbeing. After a disaster, a mother's key focus is often to re-establish a sense of normality for her children, gaining a sense of domestic routine within their family unit (Ariyabandu, 2009; Islam et al., 2017). This is 
often hampered by the physical realities of the post-disaster environment, for example, road and school closures. Crucial to reestablishing routines and supporting the social aspects of recovery is a community's ability to mobilise resources that aids with adaptive coping (Warchal \& Graham, 2011).

A strong sense of attachment after a disaster can assist in recovery (Shin, Nakakido, Horie, \& Managi, 2016). Aspects of resilience and sense of attachment to place, social relations and identity underpin a positive outlook to recovery (Chandler, 2014). Literature on social networks postdisaster highlights the importance of strong connections and belonging to a community (McManus, 2015; Paton, Selway, \& MamulaSeadon, 2013). Studies conducted in Christchurch have shown that people who could stay in their communities after the earthquakes described a cohesive, purposeful community with shared objectives (Gawith, 2011; McManus, 2015). Understanding a mother's sense of attachment to their community can offer an insight into how a relationship or connectedness to a location impacts upon their disaster recovery. This view is supported by Drolet et al. (2015) who stated that mothers who found themselves displaced and subsequently without social networks missed having the opportunity to build networks, have a sense of purpose and mingle with likeminded others. Christchurch was flooded with opportunities to engage with talking therapy after the earthquakes; however, it was reported that most women did not feel the need to relive their experiences; rather they wanted to focus on surviving and being purposeful (Gordon et al., 2014; McManus, 2015).

Research after the Christchurch earthquakes stressed the importance of cultivating a sense of belonging or affiliation to a group or community to recover successfully (Gawith, 2011; Maher \& Maidment, 2013; McManus, 2015). According to research by Phibbs, Kenny, and Solomon (2015), for a community to recover from disaster it must not stagnate, but be proactive in focusing recovery efforts, including formulating community infrastructure and working together to organise practical support for vulnerable groups. In doing so, it provides an opportunity to recover and be successful in recovery during a future event.

After the Christchurch earthquakes, population movements threatened already established networks which were essential for resiliency and recovery (Paton et al., 2013). Due to this disruption, familiar bonds and networks were broken, individuals felt more displaced and in unfamiliar territory. It is during these challenging times that support is needed the most (McManus, 2015). Women often rely upon informal support networks such as friends and family for childcare, social interaction and peer support (Ariyabandu, 2009). The importance of stable, familiar relationships is key to recovery for women. These women can then identify and work together with likeminded individuals to support the recovery effort (McManus, 2015). The relocation of close family and friends consequently has an impact upon women who become isolated by frequent population changes in their community. Identifying strengths and capacities within a community enhances its response to the disaster and supports its recovery (Gil-Rivas \& Kilmer, 2016; Paton \& Johnston, 2006).

\section{Methodology and method}

\section{Study design}

A qualitative study was utilised to understand mothers' perceptions of their post-earthquake experiences. It was guided by interpretive descriptive methodology, focusing on understanding the lived experiences and sharing meanings of mothers' everyday realities of the earthquakes (Denzin \& Lincoln, 2011; Jackson, Drummond, \& Camara, 2007). Congruent with interpretive description, this study allowed the first author to engage with mothers who described the phenomenon of the Christchurch earthquakes and 
provided a fundamental source of insight into experience and resilience. In addition, this was insider research, as the first author was a mother who had experienced the two earthquakes. This insider status allowed the first author to relate to her participants and have an appreciation of the experiences described by the participants.

\section{Participants and setting}

Purposive sampling was used to select a small group of participants, based on specific research criteria, to obtain a set of information-rich cases for in-depth analysis (Patton, 2015). The number of participants and focus of the study was limited by fact that the research was undertaken as a supervised research project as part of a master of social work qualification. The four inclusion criteria for the participants of this study were: (1) mothers over 18 years of age; (2) resident in Christchurch during the 2010 and 2011 earthquakes and were still currently living in Christchurch; (3) mothers who had not been under the care of mental health services in the last 12 months. This was to reduce the likelihood of mental distress by revisiting their experience of the earthquakes; and (4) mothers who were competent in communicating in English.

Following ethical approval from Massey University Human Ethics Committee (\#15/43), the first author contacted a local school in the Selwyn district of Christchurch, to arrange a meeting with the principal. At the meeting, the principal was provided with a copy of the information sheet and interview schedule. The principal agreed for the research to be advertised in the following week's school newsletter. Between July 2015 and February 2016, six mothers were successfully recruited and participated in the individual interviews.

The six participants were female, married, and aged between 25 and 40. Four of the participants self-identified as New Zealand Pākehā and originally from Christchurch, while the other two were from overseas.
This selection bias may be due to the fact that only $6 \%$ of the population living in Selwyn district were Māori and less than 1\% of New Zealand's Māori population usually live in the Selwyn district (Statistics New Zealand, 2013). All of the participants reported to have lived in Christchurch and had children who were school age or younger at the time the study was conducted. They were all present in Christchurch during the September and February earthquakes. Four of the participants were in paid work at the time of the earthquakes.

\section{Data collection}

The first author conducted all the face-toface, semi-structured interviews. These were between 50 to 60 minutes' duration at a mutually agreed location. All interviews were digitally recorded with the participants' prior knowledge and signed consent, and confidentiality was assured. The use of semi-structured interviews involved an informal, interactive process that utilised open-ended comments and questions (Patton, 2015). Open-ended questions were deemed the most appropriate in encouraging the participant to speak freely about their experiences from their own perspective.

The first author was responsible for establishing the research encounter as a place in which the participants could safely describe experiences that mattered to them and were pertinent to the research. The interview schedule was developed with guidelines and prompts to initiate discussion. Bonner and Tolhurst (2002) state the interpretive researcher must create a dialogue between practical concerns and lived experiences through engaged reasoning and imaginative dwelling in the immediacy of the participants' worlds. The questions were formulated by identifying key issues and components that were prevalent in literature about the Christchurch earthquakes. Questions were created to encourage mothers to reflect on their experiences of the earthquakes and to elicit information about their feelings, experiences 
and beliefs. The objective of each interview question was to obtain the participants' thoughts and feelings to understand their experiences of the earthquakes.

\section{Data analysis}

Data were analysed using an interpretive, descriptive approach underpinned by thematic analysis. In qualitative research, data collection and data analysis can occur concurrently as the interviewer identifies similar themes and notes them after an interview (Braun \& Clarke, 2013). The benefits of data collection and analysis concurrently allows for exploration of new concepts that emerge across the remaining interviews. The first author analysed the interview data for patterns and themes, which assisted them to learn about a specific group within society after the earthquakes, namely Christchurch mothers. Data were then coded to illuminate important sections of text relevant to the research objectives and categorised into themes. These themes were then linked back to the original research objective regarding understanding mothers' post-disaster experiences. The first author was conscious to ensure she did not overidentify with participants' experiences and assume the shared understanding or feelings about the earthquakes as suggested by Ross (2017). To safeguard this, confirmability was achieved by the second and third authors when consensus was reached on the data. Further to this, the second and third authors read the findings to ensure they explicitly represented the data (Tobin \& Begley, 2004).

\section{Ethical considerations}

The research was conducted in accordance with guidelines set out by Massey University's code of conduct for research with human participants. The rationale for excluding mothers who had recently been under the care of mental health services was to ensure undue mental distress was not caused to anyone by revisiting experiences of the earthquakes. It is crucial for social researchers to clarify their research roles, especially for those utilising qualitative methodologies to make their research credible (Grbich, 2013). As noted previously, the first author in this research was an insider due to also being a mother who experienced both Christchurch earthquakes. There are advantages and disadvantages to being an insider during the research process depending on the researcher's role, the aim of the research and the type of research conducted. While there are a variety of definitions for insider researchers, generally, insider researchers are those who choose to study a group to which they belong, while outsider researchers do not belong to the group under study. Bonner and Tolhurst (2002) identified key advantages of being an insider researcher which included having a greater understanding of the culture being studied and the ability to understand the emotions of those involved. Further, insider researchers know how to best approach people they wish to study. In general, they have a great deal of knowledge which takes an outsider a long time to acquire. Although there are various advantages of being an insider researcher, there are also problems. For example, greater familiarity can lead to a loss of objectivity. Over-familiarity can include unconsciously making wrong assumptions about the research process based on the researcher's prior knowledge, which can be considered a bias (DeLyser, 2001; Hewitt-Taylor, 2002). Any concerns regarding bias were addressed though discussion with the second and third authors.

\section{Results and key findings}

The three main findings that emerged from the data were: 1) elements of resilience including focusing on positive outcomes, having plans and showing determination were essential to supporting recovery after the earthquakes; 2) mothers played a constructive and proactive role in their community post-disaster; and 3) the mothers all placed importance on having a sense of belonging to enhance post-disaster recovery. These key findings offer insights into how 
mothers recover after a disaster. The findings provide information about what context, conditions and factors these mothers found most helpful in their recovery, including what assisted them to re-establish family cohesion, manage parenting challenges and support their own community to return to 'normal'.

1. Elements of resilience including: focusing on positive outcomes, having plans and showing determination were essential to supporting recovery after the earthquakes

Findings from this study revealed that these mothers' resilience and recovery were built through focusing on positive outcomes, having plans and being determined in the days, months and years after the earthquakes. Initially, disturbed nights and lack of infrastructure, including lack of power and water, meant the immediate priority for most respondents was making decisions about their physical environment. For all participants, getting back to a sense of normality in the days after the earthquake was essential. Most respondents felt that, to recover quickly, it was their responsibility to plan and develop routines for their families as quickly as possible. Clare discussed how for her family: "routine was very important. I had to show the kids that life goes on and mum and dad still go to work". This concurs with McManus's (2015) study on the Christchurch earthquakes and Islam et al.'s (2017) research on the Bangladesh floods, whereby women came together and formulated plans regarding how best to support their family and their community.

All the mothers interviewed for this study showed strength and resilience during the earthquakes, despite the scenes unfolding around them; for example, Cathy, who was at work during the February earthquake, ensured the safety of herself and her student whilst on the fourth floor of the university building. Clare's first thought was for her family; however, once she knew they were safe she turned her attention to whom she could assist. She said, "I was fearful for my life, I thought this was it... as soon as I knew the kids and my husband were okay I went straight to the ambulance area to see how I could help." Mary, who was with her children at home in February, threw herself on top of her children to protect them from falling debris. While Beth initially could not get hold of her husband due to problems with telecommunication, she had to maintain a calm exterior in front of her son. She said it was only after her son went to bed she could "have a little cry and discuss my fears with my husband." The findings in this study demonstrate that the participants were capable women with innate strength and courage, trying to function in a challenging environment despite their fears.

For the participants in this study, there is little doubt that life changed because of the earthquakes. Sam and Mary had reframed these experiences as finding a new lease of life through making new friendships and engaging in new opportunities. Both of these mothers said they could do this because they focused on the positives in the situation. Two other mothers showed the ability to reframe and overcome a difficult situation when their children's school was closed. Clare helped facilitate a temporary school in her community, whilst Beth travelled long distances to take her child to school. It appeared that mothers who were focused and positive about the future had recovered beyond their previous psychosocial position and improved their lives overall. For example, Mary reported a better work-life balance; Sam and Mary learnt new skills, while Beth found a strong cohesive community in a new environment which she had not encountered before the earthquakes. This concurs with studies that suggest that to thrive in the face of adversity, individuals need to be goal oriented, focused and have good problem-solving skills (Paton \& Johnston, 2006). Those who can be positive during the event can have the opportunity to thrive in the face of adversity and return to an improved position prior to the event happening (Greene \& Greene, 2009). 
2. Mothers played a constructive and proactive role in their community post disaster

A recent study by Gordon et al. (2014) indicated that post-disaster management in Christchurch identified women as strong and capable and an important part of the recovery effort, encompassing key roles in fostering and developing resilience within communities. While power, water and sewerage were lost to many Christchurch homes, it was not long before the local community and local agencies rallied together to support one another (Gordon et al., 2014; McManus, 2015). This study also found that mothers played a constructive and proactive role in their community after a disaster. Mothers in the current research engaged in domestic tasks but, in addition, were proactive in the wider recovery effort. Sam, Clare and Mary were actively involved in supplying food through cooking and baking, organising water supplies and rebuilding community support structures, alongside taking care of their own family.

Recognising and harnessing the capabilities of women increased their confidence for dealing with adversity (Ariyabandu, 2009). Over half of the mothers identified that having a sense of purpose within their community was important in their recovery. Clare took a lead role in managing recovery and instigated emergency measures in her community, which included organising a communal water point, whilst another participant checked on elderly neighbours. Clare identified that she was a key supporter and contributor in her community during both earthquakes. She said, "I felt because I am a nurse that I should be available as a primary support person in the community and at work." Clare reported she was well known in the community particularly after the September earthquake and because of this people found it easy to ask for help or talk to her about their concerns.

Despite extensive impacts, the mothers in this study showed characteristics of resilience including adaptability, flexibility, and optimism and coping skills which supported their recovery. Gordon et al.'s (2014) research highlighted the adaptability and flexibility of women and they were foregrounded as a group actively in charge of their own recovery. When a mother has gone through adverse events feels more selfconfident and shows ability in self-efficacy, she is more likely to have stronger adaptive capacity (Gordon et al., 2014). Alongside managing their own difficulties following the event, many of the mothers had become involved in the community recovery effort to help others.

3. The importance of a sense of belonging to enhance post-disaster recovery

Findings from this research have illustrated the constructive and proactive role mothers play in the community. The importance of building resilience at individual and community levels is supported by existing literature including Islam et al. (2017) who states that, being part of a community builds individual confidence, strength, cohesion and is essential for post-disaster recovery. For mothers who found themselves displaced and subsequently without social networks, having the opportunity to build networks, have a sense of purpose and mingle with others helped to develop social capital and resilience (Drolet et al., 2015). The innate resilience of individuals fostered and built resilience within communities. The proactivity of mothers within their communities also highlighted important components in their recovery journey.

The earthquakes and subsequent damage to properties and neighbourhoods resulted in relocation and population change for a large part of Christchurch. After the February 2011 earthquake, many school and preschool facilities were closed or relocated elsewhere and mothers found themselves in unfamiliar environments, without their usual support networks. Clare explained how she and her family found themselves having to manage on their own very soon after the earthquake 
as her key supports moved away: "my parents and sister moved away straight away despite what my family might need." Clare's experience was not unique and, increasingly, mothers found themselves without social, psychological, or practical support. Mary stated she felt lonely and isolated when one of her good friends left for Australia: "She said she just couldn't cope with the earthquakes. I don't blame her I guess as I knew she couldn't stay, but I still miss her even after all of this time."

Mothers identified that coming from, and belonging to, a community was very important to them. Literature about place attachment discussed the sense of belonging to a location, such as a house or specific area (Shin et al., 2016). Whilst most mothers in this study reported they had moved away temporarily after the earthquakes, all of them returned and adapted to the changed environment despite the altered physical and social situation. Beth said: "it crossed our minds to move away permanently but until we knew about the house and what was happening with it we couldn't go.....and then things settled down and we decided to stay as my husband had a job and we had a mortgage here." Four of the six mothers felt strong connections to the community in Christchurch and, as they reported, they had not considered relocating elsewhere. Mary explained that she was born and bred in Christchurch and: "this is where I'm from. I'm not sure where else I would go."

Disaster literature highlights that networks and friendships are significant for women in engendering a sense of belonging (Ariyabandu, 2009; McManus, 2015). Clare and Cathy said that friendships and the opportunity to connect with likeminded others was an important component to their wellbeing. Most of the respondents identified that they had been impacted negatively by the displacement of their communities. These impacts included losing their sense of belonging to a community, which subsequently resulted in them feeling more isolated. Beth said she now had limited opportunities to identify with her peer group to engender support. She talked about the informal catch-ups she used to have when picking her child up from day care which was no longer an option as it had closed. She said, "I missed the little catch ups we used to have at drop off and pick up...silly really but you don't realise how much that social contact matters until it's not there anymore." Much of the infrastructure including the local doctors, dentist and corner shop near where Beth lived was closed due to safety concerns and, because she was made redundant, she lost contact with colleagues. Beth described her sadness when she said, "I even had to find a new GP as our surgery closed. I had been with her for 20 years."

Two of the respondents could identify networks they had formed because of the earthquakes that had assisted them with their recovery. Clare said she had formed "strong relationships with those in her community that stayed after the February earthquakes." She explained how the community had worked successfully to set up support networks in the area, something which kept her focused. Cathy was also able to identify new friends and supports she had made with neighbours who had initially assisted her after the earthquakes. She explained how they had "agreed to check and secure each other's and other neighbours' houses" if another event occurred.

\section{Implications for social work practice}

Resilience is an essential capacity for successful recovery post-disaster, such as the Christchurch earthquakes (Reivich \& Shattẻ, 2002). Findings from this study revealed that resilience is possible when individuals and communities focus on positive outcomes and show determination in the wake of tragedy. This is further evidenced in McManus's (2015) study on the Christchurch earthquakes and Islam et al.'s (2017) research on the Bangladesh floods, whereby women came together and formulated plans regarding how best to support their family and their community. 
Literature has highlighted the perception that mothers have historically been considered as vulnerable and in need of additional support post-disaster (Ariyabandu, 2009; Paton \& Johnston, 2006). Findings, in this study, have highlighted that women are independent, strong and autonomous in their approach to recovery despite gender inequality and additional pressure they face in their parenting roles. Social work can make an important contribution in challenging the inequalities that exist during and after disasters (Pease, 2014). This can be achieved by exploring factors which impact on key areas of gender and disasters, namely, different impacts on men and women, male domination in emergency response and the impact of disasters on gender roles and inequalities. This will provide a broader recognition of the structural causes of ecological destruction and environmental crisis. Knowledge of these will allow social workers to address these factors and support mothers to address these inequalities.

The profession of social work with its holistic and often strengths-based approaches has much to offer in disaster recovery. Social work practice values and ethics are at the forefront of emergency action (Rowlands, 2013). Social workers as advocates for the vulnerable and disadvantaged play an important part in challenging the oppression and disadvantages women face post-disaster. Women can be further oppressed in disaster events due to the limited opportunities and disadvantages associated with their perceived roles (Juran \& Trivedi, 2015; McManus, 2015). Research after the 2004 tsunami in Thailand identified that multiple factors impacted on women's recovery including encompassing multiple roles within the family, violence and sexual exploitation, while financial stress and relationship issues also had a significant impact (Norris \& Wind, 2009). Consequently, social workers whose practice is informed by feminist, culturally sensitive, emancipatory and anti-oppressive social work principles are well placed to work in solidarity with women at the local level to address these issues for the future (Pittaway, Bartolomei, \& Rees, 2007).

Historically, the helping profession has based intervention on deficits, problems and disorders associated with identified problem factors (Norris \& Wind, 2009). In contrast, other recovery research has suggested helping professions should consider psychosocial approaches which identify and channel resources that exist within and around the individual and their community (Saleeby, 2006). By focusing upon a different approach based on strengths, help is centred on reducing the negative effects brought about by people moving away, displaced communities and loss of social networks. This, in turn, emphasises individual capabilities and encouraging people to get on with their lives independently, affirming and developing positive values and commitments, as well as making and finding membership in a community (Saleeby, 2006; Satici, 2016). It is anticipated this approach will assist individuals to recognise their inner capabilities, capacity for strength and establish knowledge that can assist them to move forward independently if faced with adversity in the future. By doing so, they can be independent and autonomous in managing their own recovery.

Individuals in the helping profession can assist people to develop the abilities and characteristics that make up resilience (Reivich \& Shattẻ, 2002). Hardship and challenge are perceived by some professionals as both a risk factor and an opportunity for growth. The strengths perspective focuses on strengths and capacities of people rather than on crisis and disadvantaged societies (Saleeby, 2006). Guo and Tsui's (2010) study established that utilising a strengths approach can encourage individual resiliency during periods of adversity and argued that social workers must cultivate and enhance the strengths of their service users to enhance resilience. In doing so individuals will be less reliant on government interventions post disaster and be able to act autonomously managing their 
own experience and recovery. The objective of strengths-based practice is that people will become more resourceful, individually and collectively, as they begin to discover newfound confidence after having survived and surmounted these difficulties independently. Recognition of individual strengths promotes individual and community resilience and provides a "bottom up" approach to adversity (Chandler, 2014). A change of perspective encouraging self-autonomy and resilience to manage the after-effects of disaster is crucial.

Social workers operating in the post-disaster phase can also support the opportunity for women to create formal and informal support networks (True, 2013). Participants in this study spoke about the importance of these networks to their immediate and ongoing recovery. The networks often occurred spontaneously, driven by community members in response to the immediate needs of the community, for both physical resources and emotional connection. Women are typically more involved than men in caring work around the home. Social networks, thus, are critical to their livelihood strategies, as well as to their mental health and resilience. Research has argued that reducing isolation is a key to unlocking the potential that is to be found in collective power (Drolet et al., 2015).

Social workers can facilitate opportunities for communication for women to connect and encourage those around them to build social capital. In addition, social workers can offer a community participatory approach which is in keeping with the social justice and human rights principles in social work. Among other things, these principles include a commitment to facilitate the inclusion of marginalised, socially excluded, dispossessed, vulnerable and at-risk groups of people and to encourage individuals to engage in advocacy about relevant local, national, regional and/or international concerns (Pittaway et al., 2007). Social workers can work alongside individuals and communities to build and support networks.
Utilising a community participatory approach as well as skills in effectively advocating and navigating systems, creating potential to support, resource and formalise community initiatives, cementing relationships, and creating continuity and connectedness for communities in what can be a chaotic and disconnected environment. Experiencing a disaster can impact individuals' sense of power and control, social workers have the ability to use the person-in-situation conceptualisation to help rebuild control and develop a sense of safety in their environments (Findley, Pottick, \& Giordano, 2017). Social workers can play an important part in promoting the role of all women post-disaster and work to lobby, promote and develop opportunities for the implementation of appropriate post-disaster guidelines and response mechanisms in partnership with local communities and women's organisations (Pittaway et al., 2007). As climate change is intensifying weather conditions and increasing the frequency of natural disasters across the globe, including in Aotearoa New Zealand, planning for safety during a disaster event and post-disaster recovery must be included in core social work practice as social workers are well placed to understand risk and safety in relation to those they work with.

\section{Limitations}

The six women who experienced both Christchurch earthquakes, while information-rich in relation to the aims of the study, were purposefully sampled and cannot be presumed to generalise to the entire population. The scope of the sample did not enable information related to sociodemographic data or ethnicity to be considered due to selection bias. The small sample size limits the generalisability of the findings to only a specific cohort and context, namely married mothers' experiences from the Christchurch earthquakes and factors that impacted on their recovery.

The use of purposeful sampling meant that the study gathered information only from 
those who had not been overly affected by the earthquakes due to their willingness to revisit the topic. The sample cohort therefore might exhibit more positive attitudes and readiness in resilience than a different cohort. Research has reported that disaster risk and recovery are known to be socially patterned and disproportionately prevalent in disadvantaged communities (Chou et al., 2004; Hemingway \& Priestley, 2014). The intersection of factors such as age, gender, disability, and income with social isolation has been found to increase vulnerability, and impede response, to natural disasters (Howard, Agllias, Bevis, \& Blakemore, 2018). Therefore, it has been suggested that national campaigns involving public education to raise awareness of disaster risk, preparation and recovery should consider specific audiences and their needs to reduce inequity and become more effective to strengthen community resilience than focusing on individual behaviour as the target of intervention (Phibbs, Kenney, Severinsen, Mitchell, \& Hughes, 2016). Despite some of these limitations, the strengths of the research include discovering key resilience characteristics of women and the methods used have arguably mitigated these limitations and offered insight into the important role women play post-disaster.

\section{Conclusion}

Mothers were affected, practically and psychologically, after the Christchurch earthquakes and additional responsibilities associated with their parenting roles created further challenges for their recovery. Despite these factors, this study found that mothers focused on ensuring the safety of their children and others in the immediate aftermath of the event and reestablished routines as quickly as possible. All the mothers in this study portrayed characteristics of resilience and most preferred to be actively involved in the recovery effort rather than utilise talking strategies to manage stress. This study found that mothers who embodied the characteristics of resilience such as positivity, hope, flexibility and adaptability coped with the challenges the event presented. Strong social networks supported their resilience alongside opportunities to be involved across all spectrums of the recovery effort were significant for many. This research has implications for social workers working within a post-disaster context including utilising an emancipatory or strengths-based approach to intervention alongside a sound understanding of community participation. These approaches support harnessing the strengths of women through a sense of belonging, purpose and opportunity for pro-activity in disaster recovery within their communities.

\section{References}

Ariyabandu, M. (2009). Sex, gender and gender relations in disasters. In E. Enarson \& P. G. Chakrabarti (Eds.), Women, gender and disaster (pp. 5-17). New Delhi, India: Sage.

Bonner, A., \& Tolhurst, G. (2002). Insider-outsider perspectives of participant observation. Nurse Researcher, 9(4), 7-19.

Braun, V., \& Clarke, V. (2013). Successful qualitative research: A practical guide for beginners. Los Angeles, CA: SAGE.

Chandler, D. (2014). Resilience. The governance of complexity. New York, NY: Routledge.

Chou, Y. J., Huang, H., Lee, C. H., Tsai, S. L., Chen, L. S., \& Chang, H. J. (2004). Who is at risk of death in an earthquake? American Journal of Epidemiology, 160(7), 688-695.

Davis, I., \& Alexander, D. (2016). Recovery from disaster. London, UK: Routledge.

DeLyser, D. (2001). "Do you really live here?" Thoughts on insider research. Geographical Review, 91(1), 441-453.

Denzin, N. K., \& Lincoln, Y. S. (2011). The Sage handbook of qualitative research. Thousand Oaks, CA: Sage.

Drolet, J., Dominelli, L., Alston, M., Ersing, R., Mathbor, G., \& Wu, H. (2015). Women rebuilding lives post-disaster: Innovative community practices for building resilience and promoting sustainable development. Gender \& Development, 23(3), 433-448.

Enarson, E. (2009). Gendering disaster risk reduction: 57 steps from words to action. In E. Enarson \& P. G. Chakrabarti (Eds.), Women, gender and disaster (pp. 320-336). New Delhi, India: Sage.

Findley, P. A., Pottick, K. J., \& Giordano, S. (2017). Educating graduate social work students in disaster response: $A$ real-time case study. Clinical Social Work, 45(2), 159-167.

Gawith, L. (2011). How communities in Christchurch have been coping with their earthquake. New Zealand Journal of Psychology, 40(4), 121-130.

Gil-Rivas, V., \& Kilmer, R. (2016). Building community capacity and fostering disaster resilience. Journal of Clinical Psychology, 72(12), 1318-1332. 
Gordon, L., Sutherland, J., DuPlessis, R., \& Gibson, H. (2014). Movers and shakers: Women's stories from the Christchurch earthquakes. National Council of Women of New Zealand. Retrieved from http://www. communityresearch.org.nz/research/movers-andshakers-womens-stories-from-the-christchurchearthquakes-final-version/

Grbich, C. (2013). Qualitative data analysis: An introduction. London, UK: SAGE

Greene, R., \& Greene, D. (2009). Resilience in the face of disasters: Bridging micro-and macro-perspectives. Journal of Human Behavior in the Social Environment, 19(8), 1010-1024.

Guo, W., \& Tsui, M. (2010). From resilience to resistance: a reconstruction of the strengths perspective in social work practice. International Social Work, 53(2), 233-245.

Hemingway, L., \& Priestley, M. (2014). Natural hazards, human vulnerability and disabling societies. A disaster for disabled people? Review of Disability Studies, 2, 57-67.

Hewitt-Taylor, J. (2002). Insider knowledge: Issues in insider research. Nursing Standard, 16(46), 33-35.

Howard, A., Agllias, K., Bevis. M., \& Blakemore, T. (2018). How social isolation affects disaster preparedness and response in Australia: Implications for social work. Australian Social Work, 71(4), 392-404.

Islam, M., Ingham., Hicks., J., \& Mancok, I. (2017). The changing role of women in resilience, recovery and economic development at the intersection of recurrent disaster: A case study from Sirjgana, Bangladesh. Journal of Asian \& African Studies, 52(1), 50-67.

Jackson, R. L., Drummond, D. K., \& Camara, S. (2007). What is qualitative research? Qualitative Research Reports in Communication, 8(1), 21-28.

Juran, L., \& Trivedi, J. (2015). Women, gender norms, and natural disasters in Bangladesh. The Geographical Review, 4, 601-611.

Maher, P., \& Maidment, J. (2013). Social work disaster emergency response within a hospital setting. Aotearoa New Zealand Social Work Review, 25(2), 69-77.

McManus, R. (2015). Women's voices: Solace and social innovation in the aftermath of the 2010 Christchurch earthquakes. Women's Studies Journal, 29(2), 22-41.

Neria, Y., Galea, S., \& Norris, F. H. (2009). Mental health and disasters. Cambridge, UK: Cambridge University Press.

Nicholls, S. (2012). The resilient community and communication practice. Australian Journal of Emergency Management, 27(1), 46-51.

Norris, F., \& Wind, L. (2009). The experience of disaster: Trauma, loss adversities, and community effects. In Y. Neria, S. Galea, \& F. Norris (Eds.), Mental health and disasters (pp. 29-46). Cambridge, UK: Cambridge University Press.

Paton, D., \& Johnston, D. (2006). Disaster resilience: An integrated approach. Springfield, IL: Thomas.

Paton, D., Selway, K. L., \& Mamula-Seadon, L. (2013). Community resilience in Christchurch: adaptive responses and capacities during earthquake recovery. Retrieved from https://www.gns.cri.nz/static/ pubs/2013/SR\%202013-037.pdf

Patton, M. (2015). Qualitative research and evaluation methods. (4th Ed). London, UK: Sage
Pease, B. (2014) Hegemonic masculinity and the gendering of men in disaster management: Implications for social work education. Advances in Social Work and Welfare Education, 16(2), 60-72.

Phibbs, S., Kenney, C., Severinsen, C., Mitchell, J., \& Hughes, R. (2016). Synergising public health concepts with the Sendai framework for disaster risk reduction: A conceptual glossary. International Journal of Environmental Research \& Public Health, 13, 1241-1262.

Phibbs, S., Kenney, C. M., \& Solomon, M. (2015). Ngā mōwaho: An analysis of Māori responses to the Christchurch earthquakes. Kōtuitui: New Zealand Journal of Social Sciences Online, 10(2), 72-82.

Pittaway, E., Bartolomei, L., \& Rees, S. (2007). Gendered dimensions of the 2004 tsunami and a potential social work response in post-disaster situations. International Social Work, 50(3), 307-319.

Reivich, K., \& Shatté, A. (2002). The resilience factor. New York, NY: Broadway.

Ross, L. E. (2017). An account from the inside: Examining the emotional impact of qualitative research through the lens of "insider" research. Qualitative Psychology, 4(3), 326-337.

Rowlands, A. (2013) Social work training curriculum in disaster management. Journal of Social Work in Disability \& Rehabilitation, 12(1-2), 130-144.

Saleeby, D. (2006). The strengths perspective in social work practice. Milwaukee, WI: Pearson/Allyn \& Bacon.

Satici, S. (2016). Psychological vulnerability, resilience, and subjective well-being: The mediating role of hope. Personality \& Individual Differences, 102, 68-73.

Shin, K. J., Nakakido, R., Horie, S., \& Managi, S. (2016). The effects of community attachment and information seeking on displaced disaster victims' decision making. PLoS One, 11(3), e0151928.

Statistics New Zealand. (2013). 2013 Census quickstats about a place: Selwyn district. Retrieved from http:// archive.stats.govt.nz/Census/2013-census/profileand-summary-reports/quickstats-about-a-place. aspx?request_value $=14888 \&$ tabname $=$ Populationandd wellings

Tobin, G. A., \& Begley, C. M. (2004). Methodological rigour within a qualitative framework. Journal of Advanced Nursing, 48(4), 388-396.

True, J., (2013). Gendered violence in natural disaster: Learning from New Orleans, Haiti and Christchurch. Aotearoa New Zealand Social Work, 25(2), 78-89.

van Kessel, G., Gibbs, L., \& MacDougall, C. (2015). Strategies to enhance resilience post-natural disaster: A qualitative study of experiences with Australian floods and fires. Journal of Public Health, 37(2), 328-336.

Warchal, J., \& Graham, L. (2011). Promoting positive adaptation in adult survivors of natural disasters. Adultspan Journal, 10(1), 34-51. 